
\title{
3 Research Square \\ Threatened salmon rely on a rare life history strategy in a modified and warming landscape
}

Flora Cordoleani ( $\nabla$ flora.cordoleani@noaa.gov )

University of California Santa Cruz / NOAA

Corey Phllis

The Metropolitan Water District of Southern California

Anna Sturrock

School of Life Sciences, University of Essex

Alyssa FitzGerald

University of California Santa Cruz / NOAA

George Whitman

UC Davis

Anthony Malkassian

Mediterranean Institute of Oceanography, Aix Marseille Université

Peter Weber

Lawrence Libermore National laboratory https://orcid.org/0000-0001-6022-6050

Rachel Johnson

NOAA / UC Davis

\section{Article}

Keywords: Spring-run Chinook Salmon, Late-migrating Juveniles, Cohort Success, Multi-year Droughts, Ocean Heatwaves, Within-population Diversity, Portfolio Effects

Posted Date: May 3rd, 2021

DOI: https://doi.org/10.21203/rs.3.rs-378191/v1

License: (9) This work is licensed under a Creative Commons Attribution 4.0 International License.

Read Full License

Version of Record: A version of this preprint was published at Nature Climate Change on October 28th, 2021. See the published version at https://doi.org/10.1038/s41558-021-01186-4. 


\section{Abstract}

Rare phenotypes and behaviors adopted by only few individuals in a population are often overlooked, yet they may serve a heightened role for many organisms coping with warming climates. In threatened spring-run Chinook salmon spawning at the edge of the species range (Central Valley, CA USA), latemigrating juveniles were critical to cohort success in years characterized by multi-year droughts and ocean heatwaves. Late migrants rely on cool over-summer river temperatures, and are thus increasingly rare due to the combined effects of warming and dam construction. Yet our results suggest, the further loss of this within-population diversity could have critical impacts to their persistence in a warming climate. Our modeling predicts that thermally appropriate river conditions to support this phenotype will shrink rapidly in the future, and will primarily occur above impassable dams. Importantly, while late migrants dominated returns in some years, interannual variability in individual growth rates and migratory strategies suggests the importance of portfolio effects for these at-risk populations. Reconnecting and maintaining diverse habitat mosaics to support phenotypic and phenological diversity will be integral to the long term persistence of this species.

\section{Introduction}

Climate change is arguably the greatest emerging threat to global biodiversity and ecosystems functioning in this period of unprecedented change ${ }^{1,2}$. To track changing climate regimes, many species have shifted their phenology ${ }^{3}$, distribution ${ }^{4,5}$, and abundances ${ }^{6}$. While there has been considerable attention given to predicting species and community-level phenological responses to climate change ${ }^{7,8}$, far less attention has been given to understanding how the loss of within population variation and rare phenotypes might modulate population resilience to future climate forcings ${ }^{9,10}$.

Phenotypic diversity is one way for populations to buffer themselves against natural or anthropogenic perturbations ${ }^{11-14}$. Plasticity in migratory timing may be particularly important for riverine species, as their ability to respond to adverse ambient conditions is constrained by the stream network, leaving fewer options for lateral movements compared with terrestrial or marine species ${ }^{15-18}$. Furthermore, in many cases, anthropogenic land use changes have restricted access to high elevation habitats that would have otherwise provided thermal refugia ${ }^{19}$.

Salmonids exhibit extensive phenotypic plasticity, which could enhance population stability against disturbances by spreading risk across time and space (portfolio effect concept ${ }^{11,13,20,21}$ ). However, multiple concurrent environmental forcings could weaken this portfolio effect and challenge species resilience to future climate chang $\mathrm{e}^{22}$. In particular, the combination of warming and habitat contraction, caused by dam construction and other water projects, has resulted in large population declines and erosion of salmon life history diversity, particularly for runs that rely on cooler high elevation habitats ${ }^{23-}$ 26. To understand how life history diversity may influence salmon resilience to climate change, we tracked the relative success of different juvenile migratory strategies in California's Chinook salmon 
(Oncorhynchus tshawytscha) populations that spawn at the southern edge of the native species' range ${ }^{27}$, in a heavily modified environment. These salmon serve as a model system for early indication of the challenges faced by cold-water fishes when access to thermal refugia has been drastically reduced ${ }^{28}$.

While juvenile salmonids at higher latitudes often spend multiple years in freshwater before emigrating to the ocean ${ }^{27,29}$, today, most salmon in the California Central Valley emigrate in their first winter and spring before river temperatures become intolerable. An exception is found among spring-run Chinook salmon that used to dominate the region before the construction of impassable dams ${ }^{23}$. Two populations still have access to high elevation reaches, and exhibit a rare phenotype where juveniles remain in the river over-summer before emigrating the following fall ${ }^{30}$. This late-migrating phenotype relies on access to cool water for the entire rearing period and is therefore most likely to be negatively impacted by warming temperatures and impaired access to high elevation reaches. Here, we used otolith strontium isotope ratios and daily growth increments to reconstruct the juvenile emigration patterns and growth rates of returning (i.e., successful) adult spring-run Chinook salmon, and to estimate the contribution of different migration strategies to the reproductive population across environmental extremes. Specifically, we reconstructed the juvenile life histories of 123 adults that returned to Mill and Deer Creeks (Figure 1 left panel) between 2007 and 2018. Some of these cohorts experienced severe droughts and warm ocean conditions (Supplementary Table S2), allowing us to explore potential mechanisms underpinning the expression and success of alternative life history strategies. We also investigated how predicted future river temperatures will affect the availability of suitable over-summering habitat and the long-term viability of the late-migrating phenotype. In summary, we show how climate change may truncate salmon life history diversity, and how the loss of the late-migrant phenotype could negatively affect the long-term resilience of threatened spring-run Chinook salmon populations.

\section{Results}

\section{The importance of rare phenotypes and life history diversity}

Otolith isotope profiles revealed three distinct juvenile life-history types (hereon referred to as "early", "intermediate" and "late" migrants; Figure 1 right panel, Supplementary Results S1), concordant with the three emigration modes observed in the juvenile trapping data (Supplementary Results S2). The three lifehistory types were characterized by significant differences in the age and size at which they exited the natal tributary (Figures 1 right panel and 2a, Supplementary Results S2). Despite leaving the natal stream considerably smaller, early migrants entered the ocean at a similar size and age to intermediate migrants, after rearing for multiple months in non-natal freshwater habitats. Late migrants emigrated out to the ocean significantly later and larger than either other phenotype (Figure 2b, Supplementary Results S2), having reared in the natal stream over the summer (mean natal rearing period $=194$ days \pm 32 days SD). Late migrants may thus experience very different freshwater, and estuarine and nearshore marine conditions, potentially resulting in differential feeding, growth and survival opportunities ${ }^{31,32}$. 
While late migrants were the least commonly observed phenotype in juvenile monitoring traps ${ }^{33}$ (Supplementary Figure S2a), they represented the majority of the returning adults (mean across years = $60 \%$; Figure $2 a$ ). Conversely, on average, $19 \%$ of surviving adults were represented by intermediate migrants (mean natal rearing period $=84$ days \pm 27 days SD) and $21 \%$ by early migrants (mean natal rearing period $=15$ days \pm 14 days SD). Importantly, the contribution rate of each life history type varied considerably among years (Figure 3$)$. Half of the return years $(2007,2008,2013)$ were represented by similar contributions of each life history type and bimodal freshwater exit sizes while during multi-year droughts and ocean heatwaves (returning 2012, 2014, 2018) the late migrants that left the freshwater during cooler fall conditions were functionally the only strategy to survive to adulthood (Figure 3; Supplementary Table S2).

Early-life freshwater growth rates were inversely correlated with emigration timing, with faster growing individuals tending to leave the natal tributary earlier, and slower growing individuals remaining for longer before migrating downstream (Figure 4a and Supplementary Results S3). Early migrant growth over the first 15 days was faster on average (mean cumulative width of first 15 increments $=37 \mu \mathrm{m}$ ) than intermediate $(32 \mu \mathrm{m})$ and late migrants $(30 \mu \mathrm{m}$; Figure $4 \mathrm{~b})$. It is interesting to note that the fastest growth rates were typically observed among the juveniles that left the natal stream earliest (within 15 days after emergence; open circle dots in Figure 4a), and thus reared in both natal and non-natal habitats. Those results are consistent with previous studies showing differential salmon juvenile growth rates and sizes across multiple migratory pathways s, $^{29,34,35}$.

\section{Thermally suitable habitat in a warming climate}

Temperature strongly influences salmonid physiology, growth and survival ${ }^{36}$. Thus populations with access to diverse water temperatures during incubation and natal rearing are predicted to exhibit increased phenotypic and phenological diversity ${ }^{37}$. To support late migrants, stream temperatures need to remain suitably cool over the summer to accommodate the extended rearing period. Mill and Deer Creek watersheds, along with upstream reaches of the Battle and Clear Creeks and the Yuba River, are among the few accessible and populated spring-run streams in the system that still provide suitable rearing temperatures to support all three phenotypes (Figure 5 top panels). In accessible stream reaches where spring run were historically present but are now extirpated, only the Stanislaus River has temperatures that could support the late migrating phenotype. Importantly, increases in spring and summer stream temperatures by 2040 (Figure 5 bottom panels) and 2080 (Supplementary Results S4) are predicted to further contract the amount of thermally suitable rearing habitat, especially along the downstream reaches of spring-run streams and the mainstem Sacramento River. Without intervention, late-migrants may only have access to $76 \mathrm{~km}$ of suitable summer rearing habitat by 2080, around half of the accessible suitable habitat during our study period (i.e., 2005-2015; Supplementary Table S3). However, suitable rearing habitat for late-migrants could be approximately tripled $(201 \mathrm{~km}$;

Supplementary Table S3) if spring run were provided access above the dams on the Sacramento, Feather, Yuba, American and Tuolumne Rivers (Figure 5). Here we used a fixed temperature threshold of $15^{\circ} \mathrm{C}$ after 
Richter and Kolmes ${ }^{38}$, yet we acknowledge that there is likely some variation in this threshold according to local water quality and food availability ${ }^{39}$.

\section{Discussion}

Here, using archived otolith tissues, we revealed how a diversity of growth rates and behaviors expressed during early life stages can shape population dynamics and resilience, via within-population portfolio effects, and why it is essential that conservation strategies developed for the recovery of vulnerable species support both common as well as rare phenotypes. The phenotypic diversity expressed by California Central Valley spring-run Chinook salmon has thus far enabled these populations to persist, despite habitat loss and degradation along their migratory corridor, warming temperatures, and an increasingly volatile Mediterranean climate ${ }^{23,40}$. We show for the first time that the late-migrating strategy is the life-support for spring-run populations during current periods of warming. Therefore, conservation priorities should be placed on supporting this rare and climate-adapted behavior to promote the long-term persistence of spring-run populations predicted to confront an increase in future climatic extremes, such as extended droughts and marine heatwaves future ${ }^{41-43}$. Late migrants likely experience very different selective pressures to the other phenotypes; for example, entering the ocean in different seasons at larger sizes potentially reduces interspecific competition and risk of mismatch with peak salmonid prey production during early ocean residence, a critical period for cohort success ${ }^{44}$.

For salmon and other species impacted by habitat contraction, restoring and maintaining a diverse mosaic of the habitats they require to support life history diversity will also be critical for their persistence ${ }^{21}$. For spring-run Chinook salmon, predicted stream temperatures under our climate change scenarios demonstrates the necessity for maintaining and expanding thermally suitable rearing habitat in order to support diverse growth rates and a broader spread of emigration timings. Spring-run Chinook salmon currently face high mortality during migration to the sea in the spring as early and intermediate migrants ${ }^{45}$, which is especially pronounced during drought conditions as evidenced by their poor representation in the adult returns in 2012, 2014 and 2018. Late migrants have evolved a drought-resilient strategy of leaving later in the fall when conditions are cooler, but they must be able to survive the heat of the spring and summer in headwater habitats. Improving access to cold water refugia, through habitat restoration and/or reintroductions to high elevation habitats above impassable dams, might be vital for preserving the late migrant life-history type now and in the climate future ${ }^{46,47}$. Substantially improving conditions along degraded migratory corridors could also be instrumental to bolster salmon resilience, particularly in wetter years when earlier migrants play an important role in population success.

\section{Methods}

\section{Otoliths microchemistry}


Otoliths were prepared at UC Davis per established techniques ${ }^{48}$. The otoliths' sagittal plane was sectioned on both sides using 600 and 1500 grit wet/dry sandpaper to expose the primordia and surrounding microstructure. The surface achieved a further fine polish using $3 \mu \mathrm{m}$ and $1 \mu \mathrm{m} \mathrm{Al}_{2} \mathrm{O}_{3}$ lapping films. Finished samples were mounted to a $1 \mathrm{~cm}$ square glass pedestal using Gorilla Glue ${ }^{\mathrm{TM}}$. The otoliths' dorsal side was photographed in 20x magnification using a Qimaging digital camera (MicroPublisher 5.0 RTV) mounted to a Olympus BX60 microscope. Following imaging otoliths were analyzed for strontium isotopes at the UC Davis Interdisciplinary Center for Inductively-Coupled Plasma Mass Spectrometry by Laser Ablation on their Multi Collector Inductively Coupled Mass Spectrometer. We used the otolith strontium isotope methods described in Barnett-Johnson et al. ${ }^{49,50}$ to reconstruct juvenile freshwater habitat-use and migration histories. In brief, the strontium isotope ratio $\left({ }^{87} \mathrm{Sr} /{ }^{86} \mathrm{Sr}\right)$ of freshwater habitats (the "isoscape") varies as a function of rock geology and weathering patterns ${ }^{51}$, and because there is no biological fractionation of strontium isotopes, the otoliths faithfully record the signature of the surrounding water and dietary sources. Strontium isotopes are a particularly powerful tool in the California Central Valley, because the spatial heterogeneity in rock types results in significant differences in isotope signatures among most of the salmon-bearing watersheds. Consequently, variations in ${ }^{87} \mathrm{Sr} /{ }^{86} \mathrm{Sr}$ and strontium concentration across Central Valley watersheds has proven useful for determining population of origin ${ }^{52,50}$ and reconstructing juvenile rearing and migration behavior ${ }^{53,54}$.

\section{Movement reconstruction}

Otolith radius was used as a proxy for fish size at natal and freshwater exit. The otolith radius for each ${ }^{87} \mathrm{Sr} /{ }^{86} \mathrm{Sr}$ measurement was estimated by measuring the distance from the otolith core to the center of each laser pit along a standardized $90^{\circ}$ axis ${ }^{48}$. Strontium isotope profiles representing changes in ${ }^{87} \mathrm{Sr} /{ }^{86} \mathrm{Sr}$ values as a function of otolith distance from the core were created for each otolith. Specific location ${ }^{87} \mathrm{Sr} /{ }^{86} \mathrm{Sr}$ threshold values were used to identify the movement of Central Valley spring-run Chinook juveniles from one rearing region to the other. These values come from a Central Valley isoscape database ${ }^{50,53,54}$. We considered four distinct regions in this study: Natal tributary (i.e., Mill and Deer Creeks), Sacramento River, Sacramento-San Joaquin Delta (hereon "Delta"), and San Francisco-San Pablo Bay (hereon "Bay") \& Ocean. We used changes in ${ }^{87} \mathrm{Sr} /{ }^{86} \mathrm{Sr}$ along the otolith transect to identify two key habitat shifts to reconstruct the size at which individuals exited (1) the natal tributary, and (2) freshwater (exit location is Chipps Island, river kilometer 73). Otolith radius at natal exit was calculated by linearly interpolating between otolith distances at the ${ }^{87} \mathrm{Sr} /{ }^{86} \mathrm{Sr}$ measurements on either side of the upper Sacramento River (point of Mill or Deer Creek exit and Sacramento River entry) strontium threshold value. We used the lowest ${ }^{87} \mathrm{Sr} /{ }^{86} \mathrm{Sr}$ value found for the upper Sacramento River region in the Central Valley isoscape database. If for a given fish this threshold was never crossed, we determined it by visually identifying the closest point to the Mill/Deer Creek habitat ${ }^{87} \mathrm{Sr} /{ }^{86} \mathrm{Sr}$ threshold value in the strontium profiles. Similarly, otolith radius for freshwater exit was calculated by linearly interpolating between otolith distances at the ${ }^{87} \mathrm{Sr} /{ }^{86} \mathrm{Sr}$ measurements on either side of the Chipps Island (point of Delta exit and Bay entry) strontium threshold value. Finally, the Sacramento River at Freeport ${ }^{87} \mathrm{Sr} /{ }^{86} \mathrm{Sr}$ value 
threshold was used to identify the migration of spring-run juveniles from the mainstem Sacramento River to the Delta.

\section{Clustering analysis}

We conducted a clustering analysis ${ }^{55}$ on the strontium profiles obtained from the otolith microchemistry analysis to investigate whether we could statistically identify groups of fish exhibiting similar juvenile rearing strategies among Mill and Deer Creek populations. Strontium profiles were considered as smooth curves or functions sampled at a finite subset of some interval (here the distance from the otolith core); the statistical methods for analyzing such data are described as "Functional Data Analysis" (FDA; see Ramsay and Silverman ${ }^{56}$ for an overview of FDA). With FDA methods each profile is modeled in an infinite functional space rather than considered as a discrete vector in a multidimensional space (as modeled in multivariate data analysis). The clustering analysis performed in this paper included the following steps:

1. A smoothing spline was fitted to each profile to predict continuous $87 \mathrm{Sr} / 86 \mathrm{Sr}$ values for otolith radius distances between 0 and $1000 \mu \mathrm{m}$ (using thespline function in $\mathrm{R}^{57}$ ). This allows the direct comparison of all Mill and Deer Creek strontium profiles of different lengths.

2. Each smoothed profile was then transformed into a functional data object, using a B-splines basis (using the fda package in $\mathrm{R}^{56}$ ).

3. A principal component analysis (PCA) was performed on those functional objects (using $f d a$ package in R). This allowed us to identify the principal modes of variation of each functional data object, and reduce data dimensions which has been shown to help for clustering pattern recognition and processing time ${ }^{55}$.

4. We used a model-based clustering method, where the data were represented by a series of Gaussian Mixture Models (GMM) for which each point was associated with a probability of belonging to each potential cluster ${ }^{58}$. The mixture model parameters were estimated using the ExpectationMaximization (EM) algorithm.

5. The Bayesian Information Criterion (BIC) was used to select the best model with the optimum cluster number (using mclust package in $\mathrm{R}^{59}$ ).

\section{Early-life growth rate estimation}

To estimate habitat-specific juvenile growth rates we measured the otolith increment widths using Image Pro Premier 9.0 (Media Cybernetics) in each isotopically distinct habitat region ${ }^{48}$. Each otolith reading was assigned a score of "certainty" on a scale of 1-5, 5 being the highest certainty. This index is a combination of the reader's confidence in the accuracy of the increment placement and the quality or readability of the image (i.e., how likely it is that another reader would get the exact same increment width measurements). Otoliths with poor readability were eliminated from the analysis. A total of 86 otoliths were used for growth rate estimations. 


\section{Central Valley spring-run streams temperature mapping}

To explore why Deer and Mill Creeks may exhibit multiple juvenile life histories and how life history expression may change with climate change, we compared current and future thermal conditions along every current and historical spring-run stream. Temperature was obtained from a mean monthly stream temperature model ${ }^{60}$. In brief, FitzGerald et al. ${ }^{60}$ employed a spatial stream temperature model to predict mean monthly stream temperature for nearly every river $\mathrm{km}$ in the western U.S. In the Central Valley, the test sample $r^{2}$ was 0.813 and the mean absolute prediction error (MAPE) was $1.024^{\circ} \mathrm{C}$. We first clipped this stream temperature dataset with the current and historical Central Valley spring-run distributions ${ }^{61}$. In general, the distribution and stream networks matched, but a few reaches with spring-run did not have stream temperature. We averaged the monthly temperature at each stream segment from 2005-2015, representing our study period. In the Central Valley, stream temperatures are predicted to increase by $0.6^{\circ} \mathrm{C}$ by 2040 and $1.0^{\circ} \mathrm{C}$ by $2080^{62}$, so we applied these deltas to the temperature dataset.

\section{Declarations}

\section{Acknowledgements}

Funding for otoliths analysis was provided by CA Sea Grant, award number: 82550-447552. Additional labor funding for the data analysis was contributed by the US Bureau of Reclamation Central Valley spring-run life cycle modelling project, agreement number: R12PG20200 and NOAA Investigations in Fisheries Ecology, award number: NA150AR4320071. Metropolitan Water District provided matching funds through salary contribution of co-author Corey Phillis. CDFW (Water Quality, Supply, and Infrastructure Improvement Act of 2014 (CWC §79707[g])) provided matching funds through salary contribution of co-author Anna Sturrock. NOAA fisheries provided matching funds through salary contribution of co-author Rachel Johnson. We would like to thank Matt Johnson, CDFW for providing Mill and Deer Creek otoliths and rotary screw trap data used in this study. The funding for the otolith collection came from the Sport Fish Restoration Act and Bureau of Reclamation.

\section{Author Contributions}

FC, CP, AS and RCJ conceived the study. FC lead data collection and analyses. FC, CP, AS, AJF, PKW, AM, and RCJ contributed to data analyses and manuscript writing. GW conducted the otolith microchemistry and microstructure analyses. AJF performed the temperature prediction modelling and AM performed the clustering analysis.

\section{Competing Interests statement}

The authors declare no competing interests.

\section{References}


1. Climate change 2007: impacts, adaptation and vulnerability: contribution of Working Group II to the fourth assessment report of the Intergovernmental Panel on Climate Change. (Cambridge University Press, 2007).

2. Kiehl, J. Lessons from Earth's Past. Science 331, 158-159 (2011).

3. Parmesan, C. Ecological and Evolutionary Responses to Recent Climate Change. Annu. Rev. Ecol. Evol. Syst. 37, 637-669 (2006).

4. Davis, M. B. Range Shifts and Adaptive Responses to Quaternary Climate Change. Science 292, 673-679 (2001).

5. Chen, I.-C., Hill, J. K., Ohlemuller, R., Roy, D. B. \& Thomas, C. D. Rapid Range Shifts of Species Associated with High Levels of Climate Warming. Science 333, 1024-1026 (2011).

6. Williams, J. W. \& Jackson, S. T. Novel climates, no-analog communities, and ecological surprises. Front. Ecol. Environ. 5, 475-482 (2007).

7. Root, T. L. et al. Fingerprints of global warming on wild animals and plants. Nature 421, 57-60 (2003).

8. Diez, J. M. et al. Forecasting phenology: from species variability to community patterns. Ecol. Lett. 15, 545-553 (2012).

9. Aubin, I. et al. Traits to stay, traits to move: a review of functional traits to assess sensitivity and adaptive capacity of temperate and boreal trees to climate change. Environ. Rev. 24, 164-186 (2016).

10. Moran, E. V., Hartig, F. \& Bell, D. M. Intraspecific trait variation across scales: implications for understanding global change responses. Glob. Change Biol. 22, 137-150 (2016).

11. Hilborn, R., Quinn, T. P., Schindler, D. E. \& Rogers, D. E. Biocomplexity and fisheries sustainability. Proc. Natl. Acad. Sci. 100, 6564-6568 (2003).

12. Fox, G. A. Extinction Risk of Heterogeneous Populations. Ecology 86, 1191-1198 (2005).

13. Greene, C. M., Hall, J. E., Guilbault, K. R. \& Quinn, T. P. Improved viability of populations with diverse life-history portfolios. Biol. Lett. (2010) doi:10.1098/rsbl.2009.0780.

14. Moore, J. W., Yeakel, J. D., Peard, D., Lough, J. \& Beere, M. Life-history diversity and its importance to population stability and persistence of a migratory fish: steelhead in two large North American watersheds. J. Anim. Ecol. 83, 1035-1046 (2014).

15. Fagan, W. F. Connectivity, Fragmentation, and Extinction Risk in Dendritic Metapopulations. Ecology 83, 3243-3249 (2002).

16. Fausch, K. D., Torgersen, C. E., Baxter, C. V. \& Li, H. W. Landscapes to Riverscapes: Bridging the Gap between Research and Conservation of Stream Fishes. BioScience 52, 483 (2002).

17. Comte, L. \& Grenouillet, G. Do stream fish track climate change? Assessing distribution shifts in recent decades. Ecography 36, 1236-1246 (2013).

18. Troia, M. J., Kaz, A. L., Niemeyer, J. C. \& Giam, X. Species traits and reduced habitat suitability limit efficacy of climate change refugia in streams. Nat. Ecol. Evol. 3, 1321-1330 (2019). 
19. Barbarossa, V. et al. Impacts of current and future large dams on the geographic range connectivity of freshwater fish worldwide. Proc. Natl. Acad. Sci. 117, 3648-3655 (2020).

20. Schindler, D. E. et al. Population diversity and the portfolio effect in an exploited species. Nature 465, 609-612 (2010).

21. Brennan, S. R. et al. Shifting habitat mosaics and fish production across river basins. Science $\mathbf{3 6 4}$, 783-786 (2019).

22. Crozier, L. G. et al. Climate vulnerability assessment for Pacific salmon and steelhead in the California Current Large Marine Ecosystem. PLOS ONE 14, e0217711 (2019).

23. Yoshiyama, R. M., Fisher, F. W. \& Moyle, P. B. Historical Abundance and Decline of Chinook Salmon in the Central Valley Region of California. North Am. J. Fish. Manag. 18, 487-521 (1998).

24. Beechie, T., Buhle, E., Ruckelshaus, M., Fullerton, A. \& Holsinger, L. Hydrologic regime and the conservation of salmon life history diversity. Biol. Conserv. 130, 560-572 (2006).

25. Gustafson, R. G. et al. Pacific Salmon Extinctions: Quantifying Lost and Remaining Diversity. Conserv. Biol. 21, 1009-1020 (2007).

26. McClure, M. M. et al. Evolutionary consequences of habitat loss for Pacific anadromous salmonids: Salmonid habitat loss and evolution. Evol. Appl. 1, 300-318 (2008).

27. Quinn, T. P. The Behavior and Ecology of Pacific Salmon and Trout. (University of Washington Press, 2018).

28. Yoshiyama, R. M., Gerstung, E. R., Fisher, F. W. \& Moyle, P. B. Historical and present distribution of Chinook salmon in the Central Valley of California, in Brown, R. L. 2001. Contributions to the Biology of Central Valley Salmonids. Volumes 1 \& 2. California Department of Fish and Game Fish Bulletin 179. 1, 699 (2001).

29. Metcalfe, N. B. \& Thorpe, J. E. Determinants of Geographical Variation in the Age of SeawardMigrating Salmon, Salmo salar. J. Anim. Ecol. 59, 135 (1990).

30. Moyle, P. B., Lusardi, R. A., Samuel, P. \& Katz, J. State of the Salmonids: Status of California's Emblematic Fishes 2017. Center for Watershed Sciences, University of California, Davis and California Trout, San Francisco, CA. http://rgdoi.net/10.13140/RG.2.2.24893.97761 (2017).

31. Woodson, L. et al. Size, growth, and origin-dependent mortality of juvenile Chinook salmon Oncorhynchus tshawytscha during early ocean residence. Mar. Ecol. Prog. Ser. 487, 163-175 (2013).

32. Satterthwaite, W. et al. Match-mismatch dynamics and the relationship between ocean-entry timing and relative ocean recoveries of Central Valley fall run Chinook salmon. Mar. Ecol. Prog. Ser. 511, 237-248 (2014).

33. Johnson, M. R. \& Merrick, K. Juvenile Salmonid Monitoring Using Rotary Screw Traps in Deer Creek and Mill Creek, Tehama County, California Summary Report: 1994 - 2010. RBFO Technical Report No. 04-2012. https://www.calfish.org/ProgramsData/ ConservationandManagement/ CentralValleyMonitoring/ CDFWUpperSacRiverBasinSalmonidMonitoring.aspx (2012). 
34. Beckman, B. R., Larsen, D. A., Lee-Pawlak, B. \& Dickhoff, W. W. Relation of Fish Size and Growth Rate to Migration of Spring Chinook Salmon Smolts. North Am. J. Fish. Manag. 18, 537-546 (1998).

35. Beckman, B. R., Gadberry, B., Parkins, P., Cooper, K. A. \& Arkush, K. D. State-dependent life history plasticity in Sacramento River winter-run chinook salmon ( Oncorhynchus tshawytscha ): interactions among photoperiod and growth modulate smolting and early male maturation. Can. J. Fish. Aquat. Sci. 64, 256-271 (2007).

36. Myrick, C. A. \& Cech, J. J. Temperature Effects on Chinook Salmon and Steelhead. Bay-Delta Modeling Forum Technical Publication 01-1. http://www.sfei.org/modelingforum/ (2001).

37. Cogliati, K. M., Unrein, J. R., Stewart, H. A., Schreck, C. B. \& Noakes, D. L. G. Egg size and emergence timing affect morphology and behavior in juvenile Chinook Salmon, Oncorhynchus tshawytscha. Ecol. Evol. 8, 778-789 (2018).

38. Richter, A. \& Kolmes, S. A. Maximum Temperature Limits for Chinook, Coho, and Chum Salmon, and Steelhead Trout in the Pacific Northwest. Rev. Fish. Sci. 13, 23-49 (2005).

39. Lusardi, R. A., Hammock, B. G., Jeffres, C. A., Dahlgren, R. A. \& Kiernan, J. D. Oversummer growth and survival of juvenile coho salmon ( Oncorhynchus kisutch ) across a natural gradient of stream water temperature and prey availability: an in situ enclosure experiment. Can. J. Fish. Aquat. Sci. 77, 413424 (2020).

40. Dettinger, M. D., Ralph, F. M., Das, T., Neiman, P. J. \& Cayan, D. R. Atmospheric Rivers, Floods and the Water Resources of California. Water 3, 445-478 (2011).

41. Cloern, J. E. et al. Projected Evolution of California's San Francisco Bay-Delta-River System in a Century of Climate Change. PLoS ONE 6, e24465 (2011).

42. Frölicher, T. L., Fischer, E. M. \& Gruber, N. Marine heatwaves under global warming. Nature 560, 360364 (2018).

43. Ullrich, P. A. et al. California's Drought of the Future: A Midcentury Recreation of the Exceptional Conditions of 2012-2017. Earths Future 6, 1568-1587 (2018).

44. Beamish, R. J. \& Mahnken, C. A critical size and period hypothesis to explain natural regulation of salmon abundance and the linkage to climate and climate change. Prog. Oceanogr. 49, 423-437 (2001).

45. Notch, J. J. et al. Outmigration survival of wild Chinook salmon smolts through the Sacramento River during historic drought and high water conditions. Environ. Biol. Fishes 103, 561-576 (2020).

46. Isaak, D. J., Young, M. K., Nagel, D. E., Horan, D. L. \& Groce, M. C. The cold-water climate shield: delineating refugia for preserving salmonid fishes through the 21 st century. Glob. Change Biol. 21, 2540-2553 (2015).

47. Ebersole, J. L., Quiñones, R. M., Clements, S. \& Letcher, B. H. Managing climate refugia for freshwater fishes under an expanding human footprint. Front. Ecol. Environ. 18, 271-280 (2020).

48. Barnett-Johnson, R., Grimes, C. B., Royer, C. F. \& Donohoe, C. J. Identifying the contribution of wild and hatchery Chinook salmon ( Oncorhynchus tshawytscha ) to the ocean fishery using otolith microstructure as natural tags. Can. J. Fish. Aquat. Sci. 64, 1683-1692 (2007). 
49. Barnett-Johnson, R., Ramos, F. C., Grimes, C. B. \& MacFarlane, R. B. Validation of Sr isotopes in otoliths by laser ablation multicollector inductively coupled plasma mass spectrometry (LA-MCICPMS): opening avenues in fisheries science applications. 62, 6 (2005).

50. Barnett-Johnson, R., Pearson, T. E., Ramos, F. C., Grimes, C. B. \& MacFarlane, R. B. Tracking natal origins of salmon using isotopes, otoliths, and landscape geology. Limnol. Oceanogr. 53, 1633-1642 (2008).

51. Hobson, K. A., Barnett-Johnson, R. \& Cerling, T. Using Isoscapes to Track Animal Migration. in Isoscapes (eds. West, J. B., Bowen, G. J., Dawson, T. E. \& Tu, K. P.) 273-298 (Springer Netherlands, 2010). doi:10.1007/978-90-481-3354-3_13.

52. Ingram, B. L. \& Weber, P. K. Salmon origin in California's Sacramento-San Joaquin river system as determined by otolith strontium isotopic composition. Geology 27, 851-854 (1999).

53. Sturrock, A. M. et al. Reconstructing the Migratory Behavior and Long-Term Survivorship of Juvenile Chinook Salmon under Contrasting Hydrologic Regimes. PLOS ONE 10, e0122380 (2015).

54. Phillis, C. C., Sturrock, A. M., Johnson, R. C. \& Weber, P. K. Endangered winter-run Chinook salmon rely on diverse rearing habitats in a highly altered landscape. Biol. Conserv. 217, 358-362 (2018).

55. Fielding, A. Cluster and classification techniques for the biosciences. (Cambridge University Press, 2007).

56. Ramsay, J. \& Silverman, B. W. Functional Data Analysis. (Springer-Verlag, 1997).

57. R Core Team. R: A Language and Environment for Statistical Computing. (R Foundation for Statistical Computing, 2017).

58. Fraley, C. \& Raftery, A. E. Model-Based Clustering, Discriminant Analysis, and Density Estimation. J. Am. Stat. Assoc. 97, 611-631 (2002).

59. Scrucca, L., Fop, M., Murphy, T. B. \& Raftery, A. E. mclust 5: Clustering, Classification and Density Estimation Using Gaussian Finite Mixture Models. R J. 8, 289-317 (2016).

60. FitzGerald, A. M., John, S. N., Apgar, T. M., Mantua, N. J. \& Martin, B. T. Quantifying thermal exposure for migratory riverine species: Phenology of Chinook salmon populations predicts thermal stress. Glob. Change Biol. 27, 536-549 (2021).

61. Schick, R. S., Edsall, A. L. \& Lindley, S. T. Historical and current distribution of Pacific salmonids in the Central Valley, CA. NOAA-TM-NMFS-SWFSC-369. (2005).

62. Isaak, D. J. et al. The NorWeST Summer Stream Temperature Model and Scenarios for the Western U.S.: A Crowd-Sourced Database and New Geospatial Tools Foster a User Community and Predict Broad Climate Warming of Rivers and Streams: STREAM CLIMATES IN THE WESTERN U.S. Water Resour. Res. 53, 9181-9205 (2017).

63. [NMFS] National Marine Fisheries Service. 5-Year Review: Summary and Evaluation of Central Valley Spring-run Chinook Salmon Evolutionarily Significant Unit. https://repository.library.noaa.gov/view/noaa/17018 (2016). 

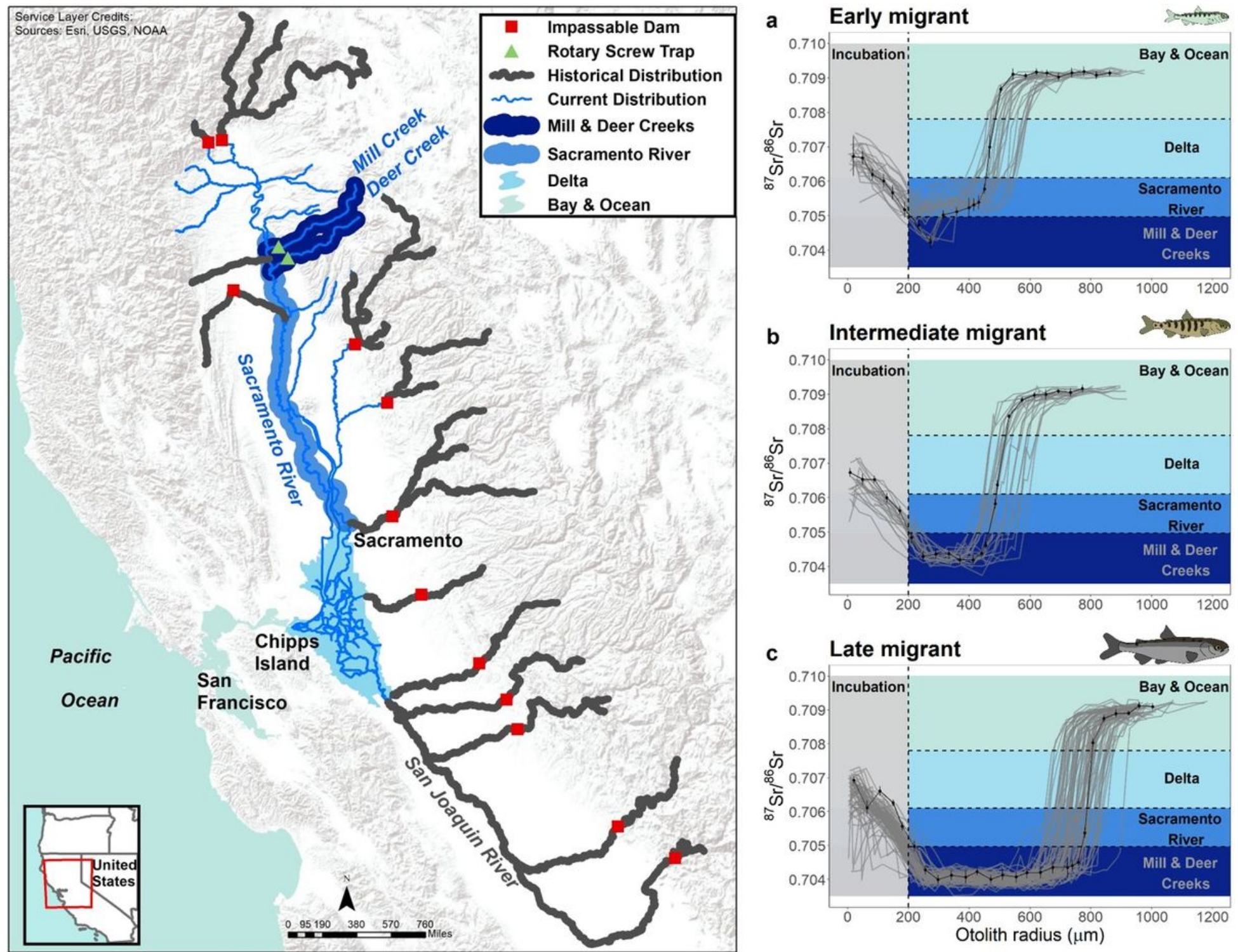

\section{Figure 1}

Spring-run Chinook salmon life history diversity. Left panel: map of historical and current distribution of California Central Valley spring-run Chinook salmon, with the two Lassen tributary populations in this study highlighted in dark blue. Delta $=$ Sacramento-San Joaquin River Delta, Bay $=$ San Francisco-San Pablo Bay. Right panel: Otolith strontium isotope profiles (grey lines) separated into early, intermediate and late migrants. Life-history types were classified using cluster analyses based on otolith isotope-byradius data for all years combined (see Methods and Supplemental Material for details). A representative profile from each cluster $( \pm 2 S D)$ is shown in bold. The first part of the profile (0 to $\sim 200 \mu \mathrm{m}$; represented by a grey rectangle) corresponds to the incubation period when the fry is nourished by the maternal yolk in the gravel. 

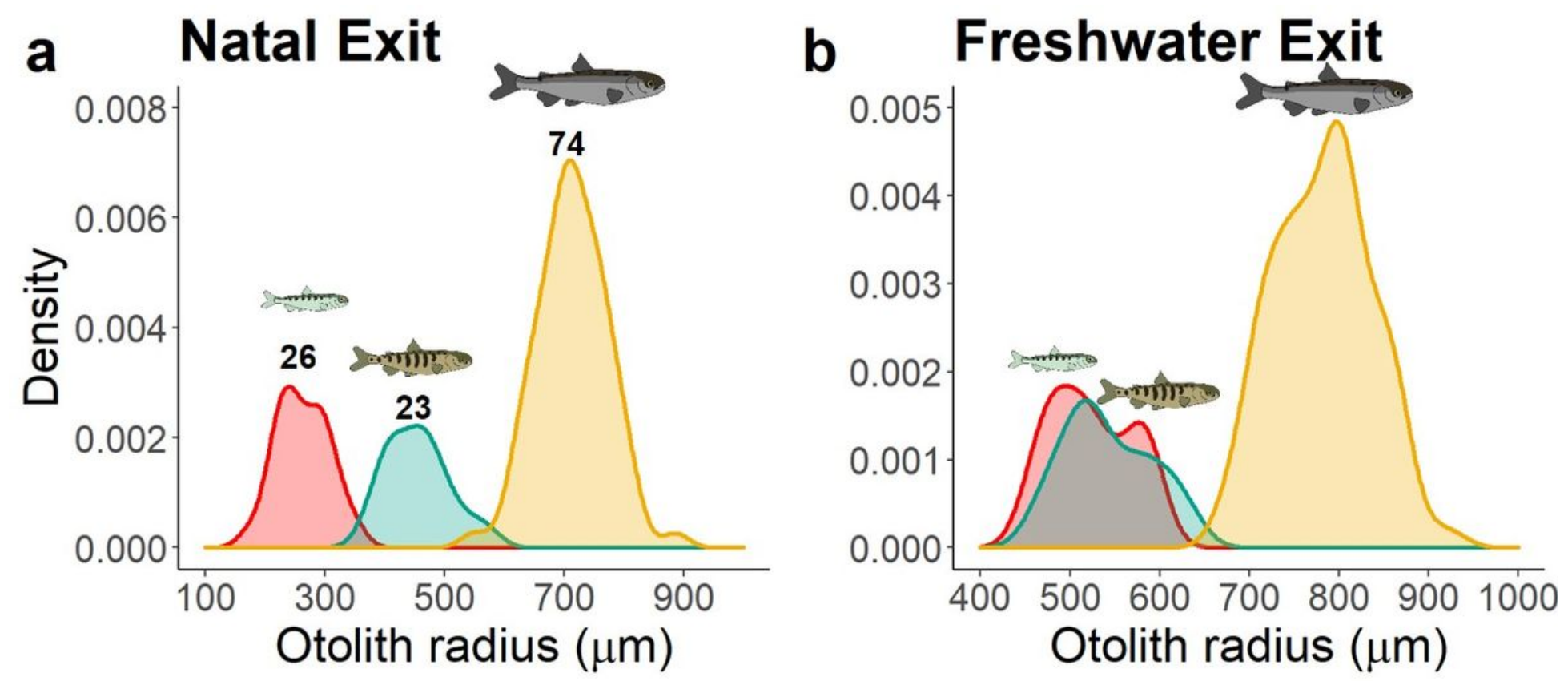

Figure 2

Migrant size distributions at natal and freshwater exit. Otolith radius (proxy for fish size) distributions for each life-history type when they emigrated out of the natal stream (a) and out of freshwater (b). Colors correspond to life history types denoted in Figure 1. Numbers above each density peak represent fish counts per life history type.

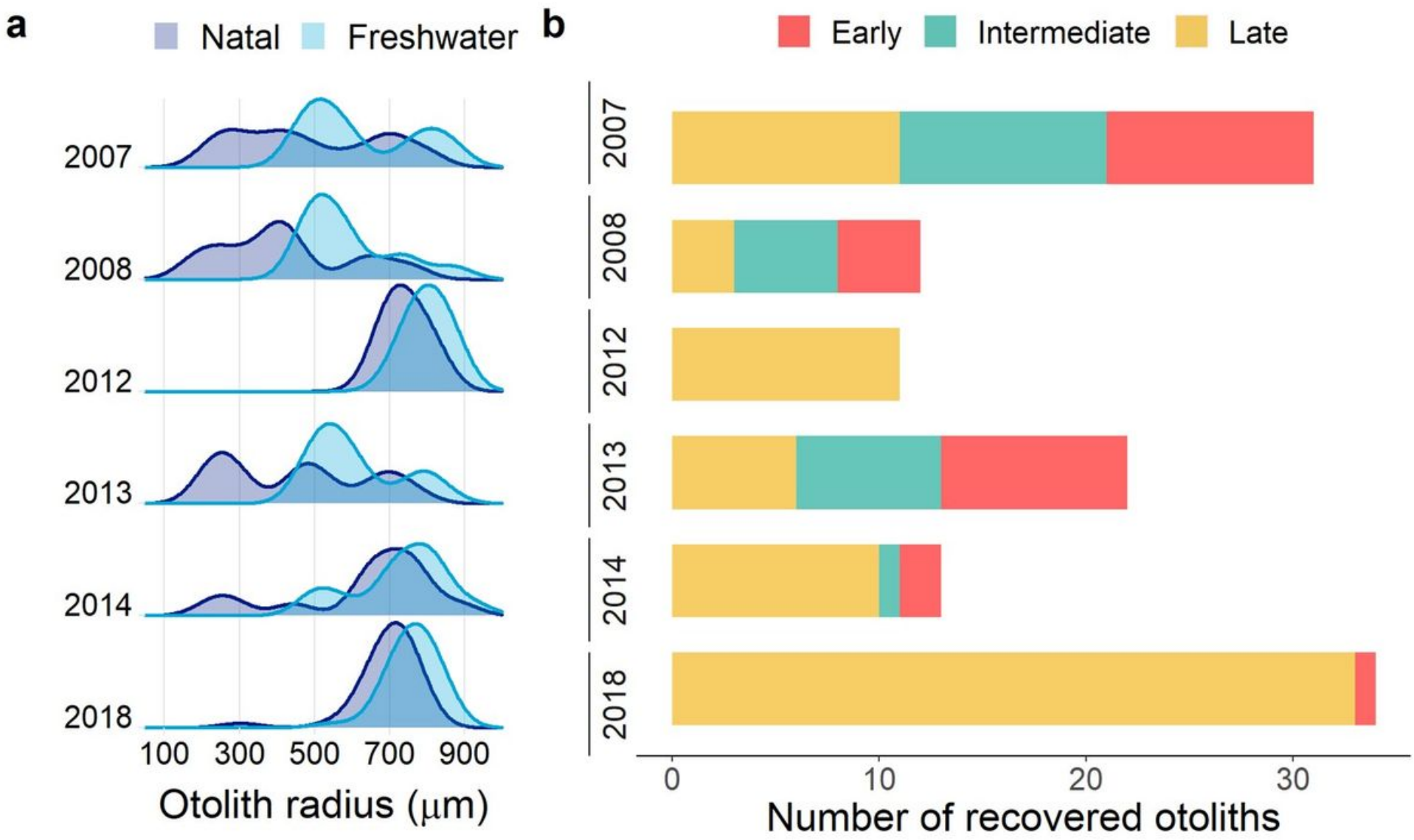


Figure 3

Migrant sizes and life history diversity across years. (a) Otolith radius (proxy for juvenile fish size) distributions for each adult return year at natal and freshwater exit, showing interannual differences in the size distribution of the juvenile emigrants that survived to adulthood. Density distributions are standardized by year. (b) Contributions of each life-history type to the adults returns. In multiple years, late emigrating juveniles comprised the majority of returning adults.
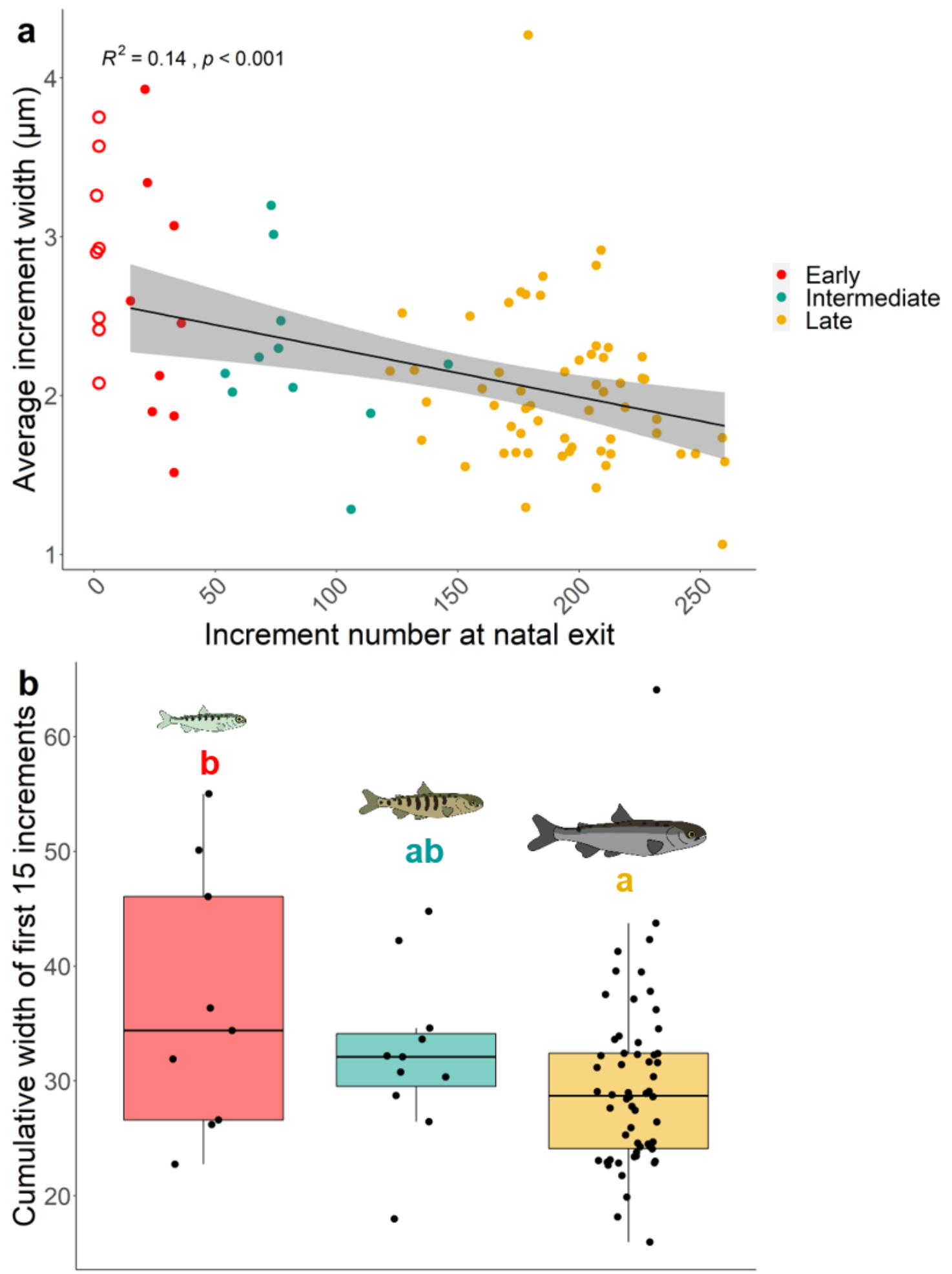


\section{Figure 4}

Early-life salmon growth across life history types. (a) Fish daily increment width (a proxy for fish growth rate) averaged over the first 15 days after emergence and plotted against the increment number (a proxy for age in days) at natal exit, for each life history type. Filled circles show individuals that were still in their natal tributary at day 15 , and used for the early-life growth analysis, while open circles represent individuals that had left their natal tributary before day 15 and reared elsewhere. A linear regression is represented by the black line, with the grey shade showing the confidence interval. Even excluding the fast-growing individuals that left before day 15 (open circles), there is a negative relationship (correlation coefficient (R) and p-value) between age at natal exit and initial growth rates. (b) Boxplot comparing cumulative increment width at day 15 (a proxy for somatic growth achieved in the first 15 days), between the three migratory phenotypes. Only fish that spent at least 15 days in the natal stream were included. Boxes not sharing the same letter are significantly different ( $p<0.05$ Tukey test). 
May - 2005-2015

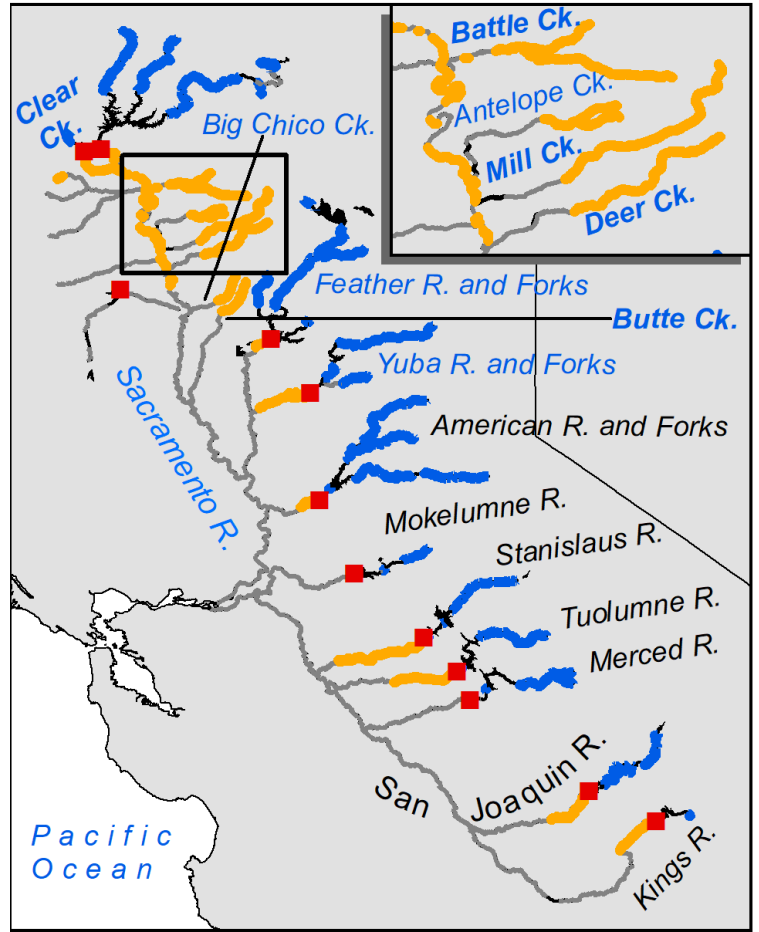

May - 2040

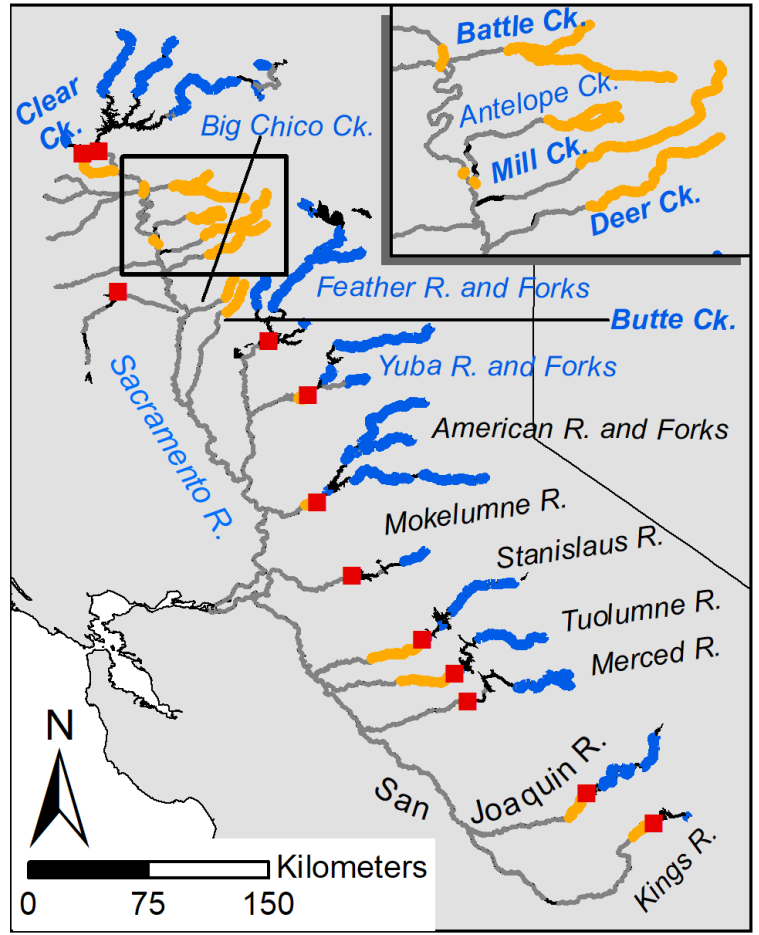

Aug - 2005-2015

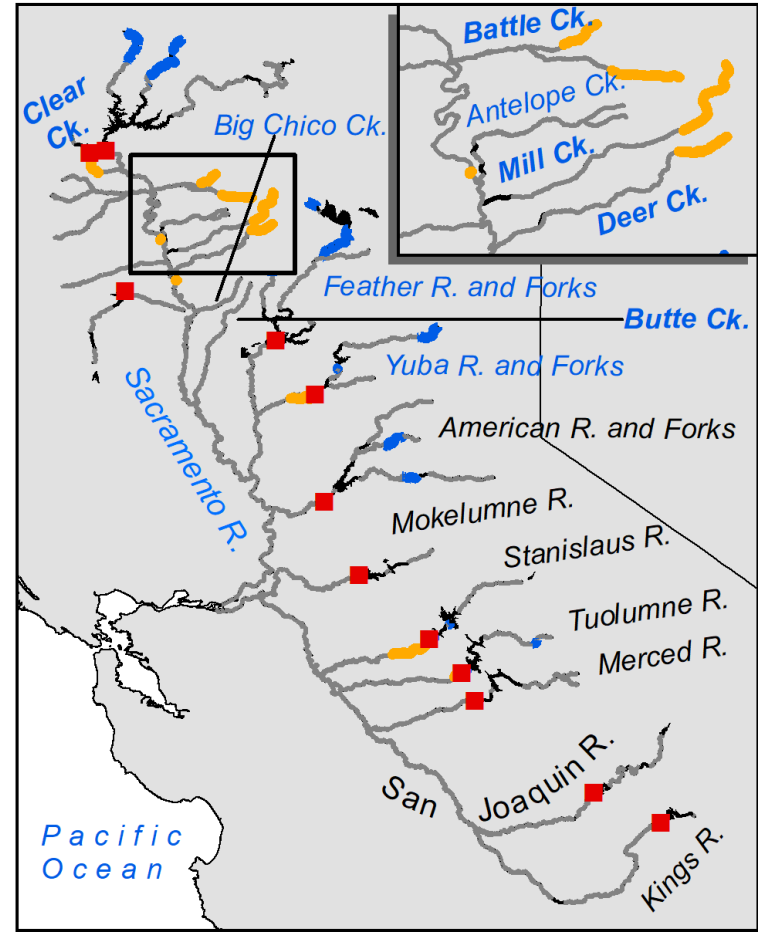

Aug - 2040

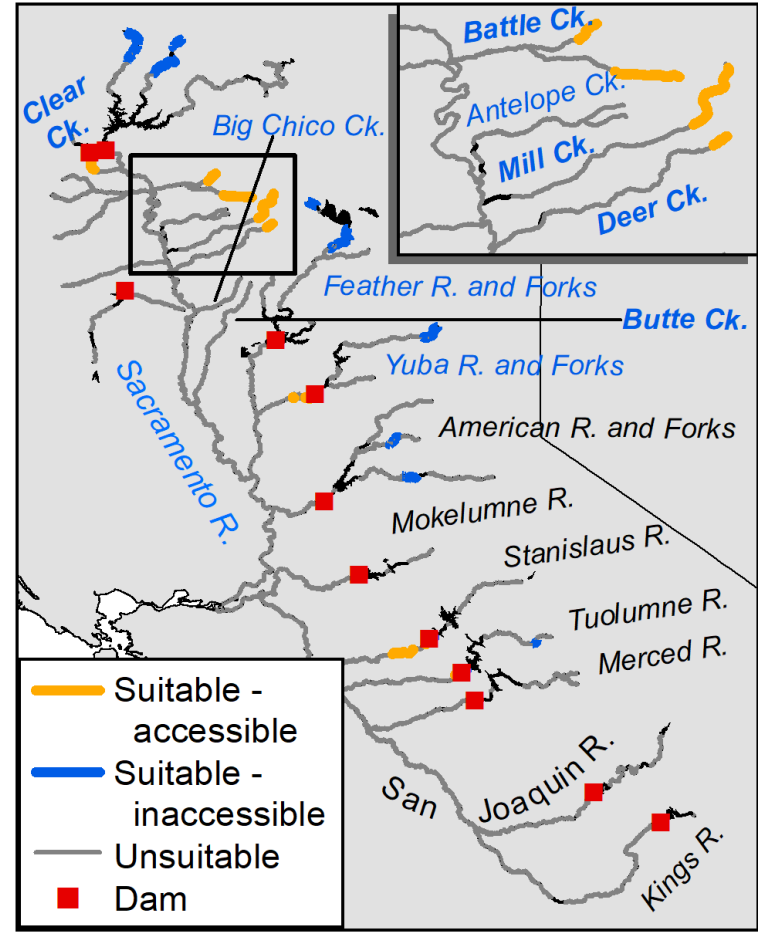

Figure 5

Central Valley habitat suitability mapping under current and future climate conditions. Rearing temperature suitability (temperature $<15^{\circ} \mathrm{C} 38$ ) in accessible (orange lines) and inaccessible (i.e., blocked by impassable dam; blue lines) river reaches in the California Central Valley, focusing on months when temperature stress is most likely to impact rearing success for early and intermediate migrants (May; left panels) and late migrants (August; right panels). We examined suitability during our study period (top 
panels) and under a future climate change scenario (2040, bottom panels). The inset maps highlight our study streams (Mill and Deer Creeks) and nearby spring-run streams. Major current and historical springrun streams are labeled, with extirpated populations in black font, and populations at low risk of extirpation63 in bold. The gray lines represent reaches that are thermally unsuitable for rearing (mean monthly temperature $>15^{\circ} \mathrm{C}$ ). The black lines represent reaches where temperatures could not be predicted reliably (e.g., reservoirs). See Methods for details on temperature mapping.

\section{Supplementary Files}

This is a list of supplementary files associated with this preprint. Click to download.

- SuppMatNaturefinal.docx 